\title{
Students' Perception About the Use of Mobile Learning in Solving Engineering Problems Collaboratively
}

\author{
https://doi.org/10.3991/ijep.v11i6.24647 \\ Islam Omirzak ${ }^{1(\bowtie)}$, Andrey Ralin $^{2}$, Boris Kasatkin $^{3}$, Lubov Vorona-Slivinskaya ${ }^{4}$, \\ Natalia Dubinina ${ }^{5,6}$ \\ ${ }^{1}$ L.N. Gumilyov Eurasian National University, Nur-Sultan, Kazakhstan \\ ${ }^{2}$ Far Eastern Federal University, Vladivostok, Russia \\ ${ }^{3}$ I.M. Sechenov First Moscow State Medical University, Moscow, Russia \\ ${ }^{4}$ Saint Petersburg State University of Architecture and Civil Engineering, Saint Petersburg, \\ Russia \\ ${ }^{5}$ Moscow University of the Ministry of Internal Affairs of Russia V.Ya. Kikot', Moscow, \\ Russia \\ ${ }^{6}$ Moscow Aviation Institute (National Research University), Moscow, Russia \\ isomirzak3erambler.ru
}

\begin{abstract}
The study is devoted to the possibility of using mobile learning for the joint solution of engineering problems by students. The research aims to determine the feasibility and perceived effectiveness of the collaborative method. The survey involved 218 students from five universities located in Russia and Kazakhstan. The results of the study show that $99 \%$ of young people have a smartphone or other mobile devices enabling Internet access, as confirmed by the study. The majority of students $(85 \%)$ believe that mobile devices can be used for learning; $65 \%$ of the young people surveyed had already used a mobile phone or tablet to study disciplines. $44 \%$ of students determine the effectiveness of this type of learning and $56 \%$ were against it. In the context of the possibility of joint solution of engineering problems through these devices, opinions were almost equally divided: $52 \%$ of students agreed and $48 \%$ of participants disagreed. The practical significance can be based on the opportunities of the use of mobile learning for the joint solution of engineering problems. The research results may be of interest to a wide range of specialists working in the field of education, as well as to developers of training programs and applications.
\end{abstract}

Keywords - distance learning, mobile devices in education, mobile learning, solving engineering problems

\section{$1 \quad$ Introduction}

Today, due to the rapid and dynamic development of technology, mobile learning is gaining popularity among the younger generation [1]. Previously, it was used as an additional tool in the learning process; now mobile learning is becoming increasingly important $[2,3]$. This learning method is often effective and, according to some researchers, can significantly improve the knowledge of students [4]. 
Recently, mobile learning has become even more popular due to the need for remote learning during the Covid-19 pandemic [5]. Experience has shown that up-todate mobile devices can provide the opportunity for lectures, practical classes, and other types of training provided that participants are in different locations in the period of distance learning required by the Covid-19 pandemic [6]. It has become an alternative to face-to-face training during the Covid-19 pandemic [7].

Mobile devices can be used as auxiliary tools in the learning process [8]. Mobile devices allow students to connect to classes and training courses anywhere and any time provided that there is Internet access [9]. In addition, mobile technologies in education help to improve technical and communication skills, find answers to the questions of interest, develop the ability to cooperate with other people, allow learners to share knowledge, and, as a result, get better academic results [10].

This study is devoted to the possibility of using mobile learning for the joint solution of engineering problems by students that can be explained by search of the solving engineering problems collaboratively that means the work together in groups with the purpose to find the decisions for the engineering problems [11,12]. This is a relevant question due to the fact that there is often a need for distance learning for various reasons as students cannot attend the university [13]. At the same time, rising specialists are required to have the skills of teamwork and collaboration that are considered to be the most important ones [14]. The joint solution of engineering problems by students through mobile learning can help young people acquire the above skills, as well as improve their knowledge and ability to address engineering problems [15].

\subsection{Literature review}

Mobile learning is a resurgence in the era of educational technology that provides informal, personal, voluntary and convenient learning opportunities for both learners and educators [16]. Mobile learning is a learning strategy that provides students with 21 st century learning opportunities to enable the use of a wide range of portable computing devices that connect via a smart classroom network or the Internet to smart components or interactive educational content and learning resources as well as this is a connection to an instructor-controlled learning environment through a Learning Management System or Social Online Learning tools to ensure a collaborative, interactive and innovative learning environment [17].

Mobile technologies embedded in new intelligent pedagogy can change the way people consider engineering education [18]. The researchers explored the nature of several smart approaches in engineering education and found out how they intersect with mobile pedagogy as well as the results showed that the use of mobile devices in educational institutions has not yet led to significant changes, and the available mobile learning largely simulates traditional approaches $[19,20]$.

The results of a study by Al-Emran and Salloum demonstrated that $99 \%$ of students have a mobile phone or a tablet as well as statistical data processing showed that there is a significant difference in the attitude of students to mobile learning that is determined by their gender: male students have a more positive attitude to mobile 
learning compared to female students, but there is no significant difference in the context of age, educational level and faculty [16].

Mobile technology can be defined as electronic devices that are small enough to fit in a pocket, such as mobile phones, personal digital assistants (PDAs), and iPods [21]. Research by Kaliisa and Picard shows that mobile learning in African higher educational institutions improves collaboration between students and teachers, enhances ongoing communication, increases student participation, contributes to authentic learning and analytical practice, as well as fosters the development of learning communities [22]. Also, in our opinion, the approaches of teachers to teaching have changed.

A study by Simonova and Poulova analyzed the use of mobile devices for learning English (for special purposes) by students of the Faculty of Computer Science and Management at the University of Hradec Králové in the Czech Republic. The researchers believe that the use of apps is part of students' life. At the same time, their desire to use these devices, as well as to pay for communication services and Internet access is important [23].

A study by Oyelere et al. focused on the exploratory approach to developing the MobileEdu app to study Computer Science in a higher education context in Nigeria as well as MobileEdu supports the ubiquitous, collaborative and social aspects of tertiary student learning. According to Oyelere's study to evaluate MobileEdu in real life learning environment, the experiment involving 142 third-year students was carried out as well as the results of the assessment are positive and showed that the MobileEdu application can improve student performance. In addition, the student learning experience was mostly positive, and students' attitude towards the Systems Analysis and Design course studied through MobileEdu was better than that of students who studied the course based on traditional methods [24].

A study by Juskeviciene et al. is aimed at considering personalized mobile learning scenarios in the field of computer engineering and other STEM disciplines in Lithuania as well the authors concluded that there is a need for pedagogical changes to improve student learning outcomes and that the key success factors in implementing mobile learning scenarios in Lithuania are: (a) identification of student learning styles; (b) identification and application of appropriate teaching tactics, methods, learning objects, tools and mobile applications in accordance with the student learning styles; and (c) the use of the correct set and sequence of teaching methods when implementing mobile learning scenarios [25].

Mobile learning is a non-formal type of learning as well as there are applications of different types: hybrid, native, and web / cloud apps [26]. According to a study by Khaddage et al. in the process of integrating formal and non-formal learning, educational institutions should not seek to formalize non-formal learning but look for unique methods and approaches to introduce mobile learning into the educational process in order to create an engaging learning environment [27].

A study by Jan et al. aimed to better understand and examine student attitudes and perceptions of the effectiveness of mobile learning in higher education as well as the study`s results show that the majority of students use a variety of mobile and 
handheld devices that can be used for mobile learning and can overcome the worst possible electricity crisis in this region of the world (Pakistan) [28].

A study by Batmetan and Palilingan tried to find out the attitude of university students to mobile learning as well as the results showed that $85 \%$ of students prefer to use the Internet privately; $78 \%$ of students are in the process of adopting mobile learning and intend to use it in the future [29]. Also the Batmetan`s and Palilingan`s research demonstrated that usability, ease of use, and ease of learning across multiple devices has a serious impact on the adoption rate of mobile education [29].

According to Kumar and Chand the amount of research related to mobile learning has been growing in recent years as well as researchers use both formal and informal methods to research student acceptance of mobile learning [30].

The results of a study by Almaiah and Alismaiel showed that quality factors, including system quality, information quality, and service quality, have a significant impact on student satisfaction and their intention to use mobile learning; perceived usefulness has an impact on the intent to use mobile learning as well as both factors have a significant effect on the implementation of mobile learning [31].

A study by Sung et al. focused on a mobile learning environment to study a local culture course in Taiwan to assess the effectiveness of mobile learning. The study showed that as a result of this approach, not only the learning environment has developed, but also local cultural identity has been popularized and student group work has improved [32].

A study by Joo et al. analyzed the relationship between factors predicting the use of the mobile learning management system (m-LMS) by online university students as well as the authors analyzed data from 222 Korean online university students on the basis of which received the results showed that perceived ease of use led to perceived usefulness [33]. Also the study by Joo determined that perceived usefulness and meeting expectations were the basis for satisfaction as well as perceived usefulness and satisfaction were the basis for the continuance intent, but perceived ease of use was not related to it; the continuance intent predicted the use of m-LMS [33].

After analyzing the above sources, it can be concluded that the use of mobile devices in universities in different countries is an important issue being widely discussed by modern researchers.

\section{$1.2 \quad$ Setting objectives}

Today, mobile devices play an important role in the life of people, especially young people [34]. This research is due to the need to check the possibility of using mobile learning for the joint solution of engineering problems by students that is defined as the search of the solving engineering problems collaboratively that means the work together in groups with the purpose to find the decisions for the engineering problems.

The purpose of the study is to determine the possibility and effectiveness of using mobile learning for the joint solution of engineering problems by students as the search of the solving engineering problems collaboratively. 
The objectives of the study are to determine the level of use of mobile devices by students; identify whether students have already used phones and tablets for learning and solving engineering problems; determine the students`opinion about the probability of effective joint solution of engineering problems by university students.

\section{Methods and materials}

\subsection{Research design and sample}

The research methodology is based on a questionnaire as well as the method of social survey based on specific criteria is the main one.

The study population was represented by 218 students that means that the sample was representative as well as it included students from different universities that gave the opportunity to determine the peculiarities of the problematic issue at different universities. The representativeness of the sample is also explained by the fact that a small number of participants allowed to study in more detail and obtain data with a higher percentage of reliability.

The survey was conducted on the basis of five universities located in Russia and Kazakhstan (Moscow University of the Ministry of Internal Affairs of Russia V.Ya. Kikot' (25 students), L.N. Gumilyov Eurasian National University (48 students), I.M. Sechenov First Moscow State Medical University (18 students), Saint Petersburg State University of Architecture and Civil Engineering (103 students), and Far Eastern Federal University (24 students)); the majority of participants were technical students, of which 99 are women and 119 are men. All senior engineering students were invited to participate in the study. It's considered that the engineering majors of the selected for the survey students were «Software Engineering», «Computer Engineering», «Biotechnology and Bioengineering», «Chemical Technologies and Engineering», «Oil and Gas Engineering and Technologies», «Agroengineering», which made it possible to identify ways to solve engineering problems in various engineering specialties to analyze the level of ownership of mobile technologies among students of different engineering specialties.

The selection of the sample is based on the age criterion as well as it was important for the study to determine the students of this age attitude to the mobile learning that's why the respondents of 20-22 years old were involved to the survey. It's considered that different amount students from different universities wasn 't taken into account as well as it didn`t influence the received results of the conducted survey in the context of the study.

Survey. The main questions of the questionnaire were:

1. Do you have a smartphone or another mobile device that enables access to the Internet? (yes/no)

2. Do you think that the above devices can be used for studying at university? (yes/no)

3. Have you previously used a smartphone or other mobile devices for learning? (yes/no) 
4. Do you think these devices make learning effective? (yes/no)

5. Do you think that a smartphone or other mobile devices can be used by students at your university to jointly solve engineering problems? (yes/no)

6. Have you had any experience of efficient (successful) solution of engineering problems through mobile learning? (yes/no)

The questions are our own development. After a practical session in the classroom, the students were handed out a printed version of the questionnaire and asked to fill it in. The activity took 15 minutes.

\subsection{Data analysis and statistical processing}

The answers of the respondents were processed with the help of Statistica and Excel programs, on the basis of which statistical data were obtained and analyzed as a percentage. In addition, the obtained results are presented in the form of tables and diagrams in order to better perceive the results of the study by the reader. Since the survey questions provided a choice of only two proposed answers - yes or no - it facilitated the calculation of statistics and increased the percentage of reliability of the results.

\subsection{Ethical issues}

The research was anonymous; the participants were not asked to indicate their names. Only age, year of study, and faculty were indicated. Before the survey, all students gave their written consent to participate in the study. The participants were explained the purpose of the research, as well as the methods of collecting and processing information received. Also the purpose of asking for the age was explained by the fact that age criterion was one of the main in the used methodology as well as it was important for us to determine the students of this age attitude to the mobile learning that's why the respondents of 20-22 years old were involved to the survey.

\section{$2.4 \quad$ Research limitations}

Due to the fact that the study involved only 218 people, its results cannot be considered universal. More participants are required to get more accurate data. It should also be noted that students from two universities (in Russia and Kazakhstan) took part in the study; therefore, the findings may not be relevant for other countries. The research results can be considered reliable, but the above information must be taken into account.

\section{$3 \quad$ Results and discussion}

The responses of the young people were as follows (table 1): 
Question 1. According to the first question (Do you have a smartphone or another mobile device that enables access to the Internet?), 215 (99\%) students have a mobile device and 3 learners do not. Of these, 97 women and 118 men answered positively. Two women and 1 man answered «No». The high percentage of young people who use mobile devices suggests that they can be used for mobile learning and collaborative problem solving. A percentage of $1 \%$ among respondents means that they do not have a smartphone or another mobile device that allows access to the Internet, which in turn indicates their unwillingness to use mobile technology in the process of learning or solving engineering problems.

Question 2. The second question (Do you think that the above devices can be used for studying at university?) showed that 186 students believe that mobile devices can be used in education and 32 students do not share this opinion. Of these, 97 women and 118 men answered positively. A negative answer was given by 19 women and 13 men, which indicates the consent and willingness of the majority of students to use mobile devices in the process of studying at university.

Question 3. The third question (Have you previously used a smartphone or other mobile devices for learning?) demonstrated that 141 students had already used mobile devices for learning while 77 students had no such experience. Of these, 67 women and 74 men answered positively, 32 women and 45 men gave negative answers. The results show that the majority of students have experience of using mobile devices to study certain disciplines. We also learned that students used to use mobile devices more for entertainment than education. However, the answers to the questions show that students used to use mobile devices also for the purpose of learning primarily to perform homework and less in teamwork. However, the answers to this question encourage the use of mobile devices in the collective work of students in order to solve engineering problems in particular.

Question 4. Ninety-five students gave a positive answer to the fourth question (Do you think these devices make learning effective?) while 123 participants answered negatively. Of these, 40 women and 55 men answered positively, 59 women and 64 men gave answer «No». The results suggest that students lack experience in mobile learning and some of them have doubts about its effectiveness.

Question 5. The fifth question (Do you think that a smartphone or other mobile devices can be used by students at your university to jointly solve engineering problems?) showed that 113 students believe that smartphones can be used to solve engineering problems while 105 participants have the opposite opinion. Of these, 44 women and 69 men answered positively, 55 women and 50 men gave negative answers. The engineering problems are considered to be connected with personal and relevant education as well as the problem of collaborative learning and its organization with the help of mobile devices. Obviously, most students do not have experience in the joint solution of engineering problems through mobile learning, but their readiness to implement this approach can be observed.

Question 6. According to the results of the sixth question (Have you had any experience of efficient (successful) solution of engineering problems through mobile learning?), 27 students have successfully solved engineering problems (personal and relevant education as well as the problem of collaborative learning and its organization 
with the help of mobile devices) through mobile learning while 191 have not. Of these, 10 women and 17 men answered positively, 89 women and 102 men gave negative answers. The results show that few students have experience in joint solution of engineering problems through mobile learning. However, their positive attitude towards this approach suggests that the initiative may be successfully implemented.

Table 1. Quantitative results of students' answers

\begin{tabular}{|l|c|c|}
\hline Question & Answer «Yes» & Answer «No» \\
\hline Question 1 & 215 & 3 \\
\hline Question 2 & 186 & 32 \\
\hline Question 3 & 141 & 77 \\
\hline Question 4 & 95 & 123 \\
\hline Question 5 & 113 & 105 \\
\hline Question 6 & 27 & 191 \\
\hline
\end{tabular}

The results of the study lived up to the expectations and do not contradict the findings obtained by other researchers. Today, most young people have a smartphone or other mobile devices enabling Internet access, as confirmed by the study $(99 \%$ of students have such a device). The majority of students $(85 \%)$ believe that mobile devices can be used for learning; $65 \%$ of the students surveyed had already used a mobile phone or tablet to study disciplines. In the context of the effectiveness of this type of learning, $44 \%$ of students spoke out in favor and $56 \%$ were against it. In the context of the possibility of joint solution of engineering problems (personal and relevant education as well as the problem of collaborative learning and its organization with the help of mobile devices) as the search of the solving engineering problems collaboratively through these devices, opinions were almost equally divided ( $52 \%$ of students agreed and $48 \%$ of participants disagreed). Only $12 \%$ of students have experience of successful joint solution of engineering problems through mobile devices.

In the comments, students indicated problems that arise in the process of using mobile devices for learning. The main problems included limited device storage capacity, which does not allow installing some applications; low battery power; too small font that does not allow users to comfortably read text, view calculations and graphs; the complexity of working with diagrams and drawings; misunderstandings between participants when solving the problem remotely; difficulties in using foreign applications as teaching methods and approach to problem-solving do not always coincide with the approaches used in users' home country (a similar result was obtained by Al-Hunaiyyan et al. [35]).

The problem of the discrepancy between the technical characteristics of mobile devices for working with educational applications and for addressing problems can be solved by using computers in the university classrooms or at home. To easily read a small font, a text or problem conditions can be printed for each student. As for foreign applications, those that have been translated into Russian (when students lack English knowledge) should be used; it is necessary to pre-select the most suitable ones or 
acquaint students with alternative approaches that are used abroad. In order to solve the problem of communication and misunderstandings in the process of remote work, an instructor (a person who will lead the process and give the floor to each student) should be appointed.

To ensure the most effective mobile learning, universities can be encouraged to create their own learning applications adapted to their own needs and a certain discipline, as well as to involve students in their development [36]. The approximate structure of a mobile application can be represented by connection of user application that is, the material base needed to conduct classes, and server application which consists of human resources. It's considered that learning according to the mobile application require student registration and teacher registration. The group of user application consists of tasks, lectures, recommended literature and extra materials (Fig. 1):

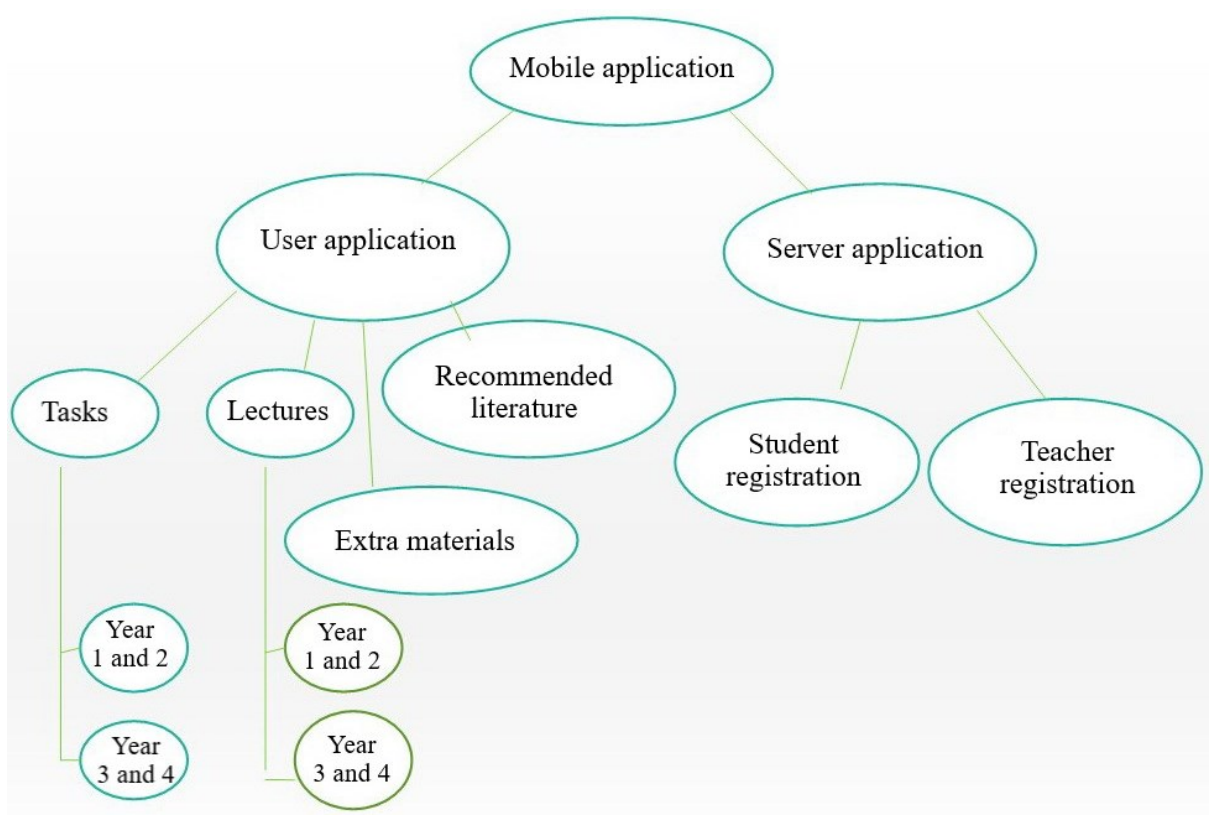

Fig. 1. The approximate structure of a mobile application

In general, mobile learning aimed at the joint solution of engineering problems by students can be implemented in the learning process; however, there is a need to monitor its effectiveness with the purpose to make sure that students take part in the solution and this learning improve the effectiveness of the educational process and can help in the development of professional competencies and skills.

Today most students use mobile devices (phones and tablets). These devices allow users to access the Internet, as well as install and use various applications, including educational ones. This suggests that mobile learning should be more widely introduced in modern universities. Equity issues can be addressed by the fact that having a mobile device is a requirement as well as the proposed program of educational pro- 
cess is based on mobile learning. Universities have equipped classrooms with the required number of computers. Given the fact that today all students have mobile devices and actively use them in everyday life and learning, there will be no problems with providing students with the material base for mobile learning, and therefore there is no need for large capital.

In addition to personal use, mobile devices also allow students to collaborate on educational projects with or without the participation of teachers (instructors). In particular, this opportunity can be used to jointly solve engineering problems by students. This has already been partially tested in the context of remote learning during the Covid-19 pandemic as well as laptops aren 't counting as mobile devices because they are considered to be the separate kind of technologies used for different purposes [37]. In addition, this opportunity can be used by a wide range of people who cannot attend school due to illness or for other reasons [38]. There are a number of programs (for example, Zoom) that allow the whole group (or several groups) to be present at a lecture or lesson. In particular, for example, such programs can be used to jointly solve engineering problems that cannot be the same as laptops because laptops are considered to be the kind of devices, on which the presented programs above can be installed.

The results showed that the majority of students $(85 \%)$ support the use of mobile devices in the process of studying at university. These results are consistent with those obtained by most other researchers, e.g., Heflin et al. [39].

Due to the fact that mobile devices have been common for a long time, many students $(65 \%)$ have already used them for learning. Not many students have used such devices to jointly solve engineering problems, but a large number of young people have experience of using mobile applications to study other disciplines, for example, foreign languages. The principle of operation of such programs and applications is clear and familiar. This gives reason to believe that students will not have serious obstacles in the study of other disciplines, as well as in joint problem solving through mobile devices.

According to $44 \%$ of students, mobile learning is effective. This result is probably based on the previous experience of students. Due to the fact that this is a minority, it is necessary to carefully consider the efficiency of mobile learning or student collaboration based on these devices. This aspect needs to be monitored [40].

Students are quite optimistic about the possible use of mobile devices for solving engineering problems. Thus, $52 \%$ believe that it is possible. This suggests that teachers can implement such classes in their groups and, in the process, observe their progress and effectiveness to make appropriate adjustments. Student acceptance of mobile learning is determined by a number of factors, such as social impact, motivation, habit, etc. [41].

Only $12 \%$ of students noted that they had previous experience in the joint solution of engineering problems using mobile learning. This suggests that this approach to problem-solving is not very popular today. This is also evidenced by the analysis of the literature on this topic. However, many researchers believe that this is one of the most relevant approaches today and that it will be widely implemented. 
According to Zarei et al. [42], engineering education in Malaysia needs to be reformed, especially in the areas of engineering programs, teaching methods and teacher training approaches in order to update it in the modern world. Mobile learning can enhance students' professional skills such as critical and analytical thinking, communication skills, and creativity. It also promotes authentic and collaborative learning [43].

According to Ivanov et al. [44], significant obstacles to mobility and distance learning of engineering students from Central Asia (for example, Tatarstan) are the Russian language, university rules, financial aspects and living conditions.

Today one of the main tasks of engineering education in Russia is to bring it in line with modern international standards in order to increase the competitiveness of graduates in the labor market, as well as to ensure the proper level of technological development and security of the country [45]. In Kazakhstan, mobile learning is developing in accordance with the "Digital Kazakhstan" state program developed on the basis of the Address of the President of the Republic of Kazakhstan N.A. Nazarbayev - The third modernization of Kazakhstan: global competitiveness dated July 31, 2017 [46].

A challenge is that students need to master skills such as written communication, speed reading, stress resistance and time management in order to effectively apply mobile learning [47].

In general, taking into account the above, we can conclude that the use of mobile learning for the joint solution of engineering problems by students is possible and promising. Teachers need to develop projects for these activities. At the same time, one of the important factors determining their use should be effectiveness. Effectiveness is determined as the correct solution of the problem, the choice of the most optimal method and the involvement of the maximum number of students (preferably all). All this should lead to an increase in the level of knowledge of students.

This research is a useful contribution to training and, therefore, to the development of the possibilities of using mobile learning in universities. In particular, the results of the study make it possible to clarify various aspects of the use of mobile devices in the process of learning and solving problems, identify existing problems and propose ways to solve them, as well as prepare a preliminary project of a mobile application for a specific educational institution.

\section{Conclusions}

The results of the study are determines that the level of use of mobile devices by students is indicated by $99 \%$ as well as all of them have mobile devices that allow them to access the Internet, which gives reason to consider a larger-scale implementation of mobile learning in the educational process. It has been identified that $65 \%$ of students have already used phones and tablets for learning and solving engineering problems. This suggests that mobile learning will also be effective in learning other sciences. A prerequisite for this is the careful and professional development of appropriate applications, online course plans and remote lessons. The results of the survey also have given the opportunity to determine the students` opinion about the probabil- 
ity of effective joint solution of engineering problems by university students. However, only $12 \%$ of the students surveyed consider this type of training to be effective in the context of solving engineering problems, and therefore it is necessary to take this into account in the process of developing online lectures and practical classes.

The study is a useful contribution to the development of mobile learning technologies and improving the quality of education in modern higher educational institutions. For further research, the development and testing of practical online classes, as well as collecting students 'and teachers' opinions on their productivity, can be recommended.

The research results can be useful for educators, educational software developers, and a wide range of people working in the field of education and educational technology. The study describes information on the use of mobile devices in the learning process at universities; problems associated with this and possible ways to solve them.

\section{$5 \quad$ References}

[1] Buabeng-Andoh, C. (2021). Exploring University students' intention to use mobile learning: A research model approach. Education and Information Technologies, 26: 241-256. https://doi.org/10.1007/s10639-020-10267-4

[2] Al-Rahmi, A.M., Al-Rahmi, W.M., Alturki, U., Aldraiweesh, A., Almutairy, S., AlAdwan, A.S. (2021). Exploring the factors affecting mobile learning for sustainability in higher education. Sustainability, 13(14): 7893. https://doi.org/10.3390/su13147893

[3] Zotova, M., Likhouzova, T., Shegai, L., Korobeynikova, E. (2021). The use of MOOCS in online engineering education. International Journal of Engineering Pedagogy, 11(3): 157175. https://doi.org/10.3991/ijep.v11i3.20411

[4] Demir, K., Akpinar, E. (2018). The effect of mobile learning applications on students' academic achievement and attitudes toward mobile learning. Malaysian Online Journal of Educational Technology, 6(2): 48-59. https://doi.org/10.17220/mojet.2018.02.004

[5] Bekithemba, D., Vusumuzi, M., Thuthukile, J. (2021). Mobile learning app in the Covid19 crisis among high school students in Zimbabwe: Construction of New Learning Conditions. Multicultural Education, 7(3): 251-258.

[6] Jacques, S., Ouahabi, A., Lequeu, T. (2020). Remote knowledge acquisition and assessment during the COVID-19 pandemic. International Journal of Engineering Pedagogy, 10(6): 120-138. https://doi.org/10.3991/ijep.v10i6.16205

[7] Vorona-Slivinskaya L., Bokov D., Li O. (2020). Visualization of learning and memorizing processes using mobile devices: mind mapping and charting. International Journal of Interactive Mobile Technologies, 14(21): 136-152. https://doi.org/10.3991/ijim.v14i21. $\underline{18475}$

[8] Nikolopoulou, K. (2021). Mobile devices and mobile learning in Greek secondary education: Policy, empirical findings and implications. In Handbook for Online Learning Contexts: Digital, Mobile and Open. Springer, Cham, pp. 67-80. https://doi.org/10.1007/978-3030-67349-9 6

[9] Aziz, S., Kadel, R., Guruge, D.B., Paudel, K., Karagiannidis, V. (2021). Mobile learning approaches and its impact on student's education - A survey. International Journal of Information and Education Technology, 11(9): 429-435. https://doi.org/10.18178/ijiet.2021. $\underline{11.9 .1546}$ 
Paper-Students' Perception About the Use of Mobile Learning in Solving Engineering Problems...

[10] Naciri, A., Baba, M., Achbani, A., Kharbach, A. (2020). Mobile learning in higher education: Unavoidable alternative during COVID-19. AQUADEMIA, 4(1): ep20016. https:// doi.org/10.29333/aquademia/8227

[11] Li, Y., Wang, L. (2018). Using iPad-based mobile learning to teach creative engineering within a problem-based learning pedagogy. Education and Information Technologies, 23: 555-568. https://doi.org/10.1007/s10639-017-9617-y

[12] Hadiana, A. (2017). Interface modeling for mobile learning using Kansei engineering and analytical hierarchy process. In 2017 International Conference on Computer, Control, Informatics and its Applications (IC3INA), pp. 153-157. https://doi.org/10.1109/ic3ina.2017. $\underline{8251758}$

[13] Schneider, S.L., Council, M.L. (2021). Distance learning in the era of COVID19. Archives of Dermatological Research, 313: 389-390. https://doi.org/10.1007/s00403020-02088-9

[14] Driskell, J.E., Salas, E., Driskell, T. (2018). Foundations of teamwork and collaboration. American Psychologist, 73(4): 334-348. https://doi.org/10.1037/amp0000241

[15] Almetov, N., Zhorabekova, A., Sagdullayev, I., Abilhairova, Z., Tulenova, K. (2020). Engineering education: Problems of modernization in the context of a competence approach. International Journal of Engineering Pedagogy, 10(6): 7-20. https://doi.org/10.3991/ijep. v10i6.14043

[16] Al-Emran, M., Salloum, S. (2017). Students' attitudes towards the use of mobile technologies in e-evaluation. International Journal of Interactive Mobile Technologies, 11(5): 195202. https://doi.org/10.3991/ijim.v11i5.6879

[17] Al-Hunaiyyan, A., Al-Sharhan, S., Alhajri, R. (2017). A new mobile learning model in the context of smart classroom environment: A holistic approach. International Journal of Interactive Mobile Technologies, 11(3): 39-55. https://doi.org/10.3991/ijim.v11i3.6186

[18] Punithavathi, P., Geetha, S. (2020). Disruptive smart mobile pedagogies for engineering education. Procedia Computer Science, 172: 784-790. https://doi.org/10.1016/j.procs. 2020.05.112

[19] Haryati, S., Rizal, F., Syah N. (2021). Meningkatkan hasil belajar siswa menengah kejuruan melalui mobile learning. Jurnal Edutech Undiksha, 9(1): 31-39. https://doi.org/ 10.23887/jeu.v9i1.31896

[20] Suryaman, H., Kusnan, K., Mubarok, H. (2020). Profile of online learning in building engineering education study program during the COVID-19 pandemic. International Journal of Recent Educational Research, 1(2): 63-77. https://doi.org/10.46245/ijorer.v1i2.42

[21] Brandt, A., Jensen, M.P., Søberg, M.S., Andersen, S.D., Sund, T. (2020). Information and communication technology-based assistive technology to compensate for impaired cognition in everyday life: a systematic review. Disability and Rehabilitation: Assistive Technology, 15(7): 810-824. https://doi.org/10.1080/17483107.2020.1765032

[22] Kaliisa, R., Picard, M. (2017). A systematic review on mobile learning in higher education: The African perspective. The Turkish Online Journal of Educational Technology, 16(1): 1-14.

[23] Simonova, I., Poulova, P. (2016). Mobile devices and applications enhancing engineering education in ESP. In 2016 13th International Conference on Remote Engineering and Virtual Instrumentation (REV). IEEE, pp. 163-167. https://doi.org/10.1109/rev.2016.7444458

[24] Oyelere, S., Suhonen, J., Wajiga, G., Sutinen, E. (2018). Design, development, and evaluation of a mobile learning application for computing education. Education and Information Technologies, 23: 467-495. https://doi.org/10.1007/s10639-017-9613-2 
Paper-Students' Perception About the Use of Mobile Learning in Solving Engineering Problems...

[25] Juskeviciene, A., Jasute, E., Kurilovas, E., Mamcenko, J. (2016). Application of 1:1 mobile learning scenarios in computer engineering education. International Journal of Engineering Education, 32(3): 1087-1096.

[26] Witthaus, G., Ryan, G. (2020). Supported mobile learning in the "Third Spaces" between non-formal and formal education for displaced people. In Critical Mobile Pedagogy. Routledge, pp. 76-88. https://doi.org/10.4324/9780429261572-6

[27] Khaddage, F., Müller, W., Flintoff, K. (2016). Advancing mobile learning in formal and informal settings via mobile app technology: Where to from here, and how? Educational Technology \& Society, 19(3): 16-26.

[28] Jan, S., Ullah, F., Ali, H., Khan, F. (2016). Enhanced and effective learning through mobile learning an insight into students perception of mobile learning at university level. International Journal of Scientific Research in Science, Engineering and Technology, 2(2): 674-681.

[29] Batmetan, J., Palilingan, V. (2018). Higher education students' behaviour to adopt mobile learning. In IOP Conference Series: Materials Science and Engineering (Vol. 306, No. 1). IOP Publishing, pp. 012067. https://doi.org/10.1088/1757-899x/306/1/012067

[30] Kumar, B., Chand, S. (2019). Mobile learning adoption: A systematic review. Education and Information Technologies, 24(3): 471-487.

[31] Almaiah, M., Alismaiel, O. (2019). Examination of factors influencing the use of mobile learning system: An empirical study. Education and Information Technologies, 23(6): 125. https://doi.org/10.1007/s10639-018-9810-7

[32] Sung, H., Hwang, G., Chang, Y. (2016). Development of a mobile learning system based on a collaborative problem-posing strategy. Interactive Learning Environments, 24(3): 456-471. https://doi.org/10.1080/10494820.2013.867889

[33] Joo, Y., Kim, N., Kim, N. (2016). Factors predicting online university students' use of a mobile learning management system (m-LMS). Educational Technology Research and Development, 64: 611-630. https://doi.org/10.1007/s11423-016-9436-7

[34] Farley, H., Murphy, A., Johnson, C., Carter, B., Lane, M., Hafeez-Baig, A., Dekeyser, S., Koronios, A., Midgley, W. (2015). How do students use their mobile devices to support learning? A case study from an Australian Regional University. Journal of Interactive Media in Education, 1: 14. https://doi.org/10.5334/jime.ar

[35] Al-Hunaiyyan, A., Alhajri, R., Al-Sharhan, S. (2018). Perceptions and challenges of mobile learning in Kuwait. Journal of King Saud University - Computer and Information Sciences, 30(2): 279-289. https://doi.org/10.1016/j.jksuci.2016.12.001

[36] Kadry, S., Ghazal, B. (2019). Design and assessment of using smartphone application in the classroom to improve students' learning. International Journal of Engineering Pedagogy, 9(2): 17-34. https://doi.org/10.3991/ijep.v9i2.9764

[37] Al-Emran, M. (2020). Mobile learning during the era of COVID-19. Revista Virtual Universidad Católica del Norte, 61: 1-2. https://doi.org/10.35575/rvucn.n61a1

[38] Singh, A., Leavline, J., Selvam, J. (2017). Mobile application for m-learning. International Journal of Advanced Research in Computer Science, 8(3): 313-316.

[39] Heflin, H., Shewmaker, J., Nguyen, J. (2017). Impact of mobile technology on student attitudes, engagement, and learning. Computers \& Education, 107: 91-99. https://doi.org/10. 1016/j.compedu.2017.01.006

[40] Alghazi, S.S., Kamsin, A., Almaiah, M.A., Wong, S.Y., Shuib, L. (2021). For sustainable application of mobile learning: An extended UTAUT model to examine the effect of technical factors on the usage of mobile devices as a learning tool. Sustainability, 13(4): 1856. https://doi.org/10.3390/su13041856 
Paper-Students' Perception About the Use of Mobile Learning in Solving Engineering Problems...

[41] Arain, A., Hussain, Z., Vighio, M., Rizvi, W. (2018). Factors influencing acceptance of mobile learning by higher education students in Pakistan. Sindh University Research Journal, 50: 141-146. https://doi.org/10.26692/surj/2018.01.0025

[42] Zarei, A., Yusof, K., Daud, M., Hamid, D. (2016). Mobile learning for engineering education reform. Sains Humanika, 9(1-2): 1-6.

[43] Wang, J., Chen, X., Gao, X. (2020). Economic management teaching mode based on mobile learning and collaborative learning. IEEE Access, 8: 200589-200596. https://doi. org/10.1109/access.2020.3033774

[44] Ivanov, V., Kaibiyainen, A., Miftahuddinova, L. (2017). Engineering education in the digital world. Higher Education in Russia, 12: 136-143.

[45] Ivanov, V., Kondratyev, V., Kaibiyainen, A. (2013). Modern problems of engineering education: the results of international conferences and scientific schools. Higher Education in Russia, 12: 66-75.

[46] Abdykarimova, A., Krivankova, L., Zheksembaeva, R. (2018). Mobile devices and applications in education: Necessity or tribute. International Journal of the Humanities and Natural Sciences, 2: 1-3.

[47] Olkhovaya, T., Poyarkova, E. (2020). New engineering education practices in the context of distance learning. Higher Education in Russia, 8(9): 142-152. https://doi.org/10. $\underline{31992 / 0869-3617-2020-29-8-9-142-154}$

\section{Authors}

Islam Omirzak is a Master of Pedagogical Science, PhD Candidate of the Department of Informatics, L.N. Gumilyov Eurasian National University, Nur-Sultan, Kazakhstan.

Andrey Ralin is a Candidate of Sciences (Physics and Mathematics), Associate Professor of School of Natural Sciences, Far Eastern Federal University, Vladivostok, Russia.

Boris Kasatkin is a Senior Teacher of the Department of Physical Education, I.M. Sechenov First Moscow State Medical University, Moscow, Russia.

Lubov Vorona-Slivinskaya is a DSc in Economics, Professor of the Department of Construction Technology, Saint Petersburg State University of Architecture and Civil Engineering, Saint Petersburg, Russia.

Natalia Dubinina is a PhD in Law, Associate Professor, Head of the Department of Computer Science and Mathematics, Moscow University of the Ministry of Internal Affairs of Russia V.Ya. Kikot', Moscow, Russia, Senior Lecture of Publicity and public relations in high-technology industries Department I-15 of the Institute of Foreign Languages of the Moscow Aviation Institute (National Research University), Moscow, Russia.

Article submitted 2021-06-08. Resubmitted 2021-09-27. Final acceptance 2021-09-27. Final version published as submitted by the authors. 